\title{
Social Media Usability and Its Impact on Buyer Purchasing Behavior Based on Buyer's Trust: Saudi Arabia Context
}

\author{
Ala'Eddin Mohammad Khalaf Ahmad ${ }^{1}$ \\ ${ }^{1}$ Faculty of Economics and Administration, King Abdul-Aziz University, Jeddah, Kingdom of Saudi Arabia \\ Correspondence: Ala'Eddin Mohammad Khalaf Ahmad, Associate Professor of Health Marketing, Faculty of \\ Economics and Administration, King Abdul-Aziz University, Jeddah, Kingdom of Saudi Arabia. Tel: \\ 966-56-852-7444.
}

Received: December 21, 2016

Accepted: January 6, $2017 \quad$ Online Published: January 15, 2017

doi:10.5430/ijba.v8n1p87

URL: http://dx.doi.org/10.5430/ijba.v8n1p87

\begin{abstract}
The current research investigates the social media usability influences on buyer purchasing behavior based on buyer's trust in Jeddah city, Saudi Arabia. This research proposes and tests a five-factor model that influences purchasing behaviors. These factors include the independent variables of social media usability, namely connectedness, openness, speed, accessibility, and participation, while the dependent variable is purchasing behavior. In order to explore this issue, a quantitative method was used in the form of a questionnaire issued in Jeddah city. The research targeted 500 respondents as a representative sample, rather than the whole population. A random sample was used to choose the participants in this research. The research retrieved 370 valid questionnaires, which represented a response rate of $74 \%$. The results confirm significant differences in the influence of these factors on purchasing behavior. The research concludes that there are significant influences from connectedness, openness, speed, accessibility, and participation.
\end{abstract}

Keywords: social media usability, buyer purchasing behaviour, Saudi Arabia

\section{Introduction}

Thetoolscalled social media, social technologies or Web 2.0 have emerged into the mainstream. As they grow, these new technologies have the opportunity to influence the methods and procedures of many fields (Spallek et al., 2010). Social networking is the process of using social media tools to collaborate, network and share electronic media among individuals across geographic and social boundaries. When used for professional purposes such as patient to health service providers collaboration or hospital system internal communication, social networking becomes professional networking. Researchers and media experts have proposed various definitions for social media. Kaplan and Haenlein (2010) give a general definition of social media in consideration of Web 2.0 and user-generated content. Social media is a group of internet-based applications that build on the ideological and technological foundations of Web 2.0 and that allow the creation and exchange of user-generated content (Kaplan \& Haenlein, 2010). Parr (2010) defines social media as the use of electronic and internet tools for the purpose of sharing information and occurrences more efficientlywith other people. Jantsch (2008) considers social media as the use of technology combined with social interaction to generate, or to share in generating, value. Social media is defined by Merriam-Webster dictionary as electronic communication by means of which users create online communities to share various content such as information, opinions and messages. According to Dykeman (2008), social media is "the means for any person to: publish digital, creative content; provide and obtain real-time feedback via online discussions, commentary and evaluations; and incorporate changes or corrections to the original content" (Dykeman, 2008, p.8). The online encyclopedia wiki defines social media in terms of social interaction, which offers tools for publishing content which are widely available and scalable. Social media use web-based technologies to transform and broadcast media monologues into dialogues. Although there are many definitions, there are three fundamental elements that support the existence and prosperity of social media, which are content, communities and Web 2.0. Social media relies on the technology. The Web 2.0 technology enables people to use various platforms to share, discuss and create contents with each other in the community. However, technology alone is useless unless it is used by people to create value. From that point of view, communities (formed by people), content and Web 2.0 are complementary and necessary to each other. Two general research questions are formulated as follows: What are the 
factors that influence Saudi people to find information about health services through social media? Do social media in social networking sites affect the buyer's trust? How does social media usability influence the purchase decisions of Saudi buyers? The current research's purpose is to investigate social media usability and its impact on buyer purchasing behavior based on buyer's trust in Jeddah city, Saudi Arabia.

\section{Literature Review}

\subsection{Social Media Usability}

Web 2.0 technology is so mature that social media has almost universal reach around the world, since all that is required is electronic devices connected to the internet. It has already been integrated into people's daily lives. However, very few people have truly understood the essence of social media. Understanding social media characteristics is important for both individuals and organizations who want to compete in the market. Buyers who have good command of social media skills and a solid understanding ofits characteristics will make their life easier and conduct themselves with additional value (individual marketing, data product seeking, employment seek, and so forth.). Organizations employing social media as part of their marketing strategy without essentially understanding the qualities of social media are bound to failure. Even though thousands of articles and blog posts have looked at social media from all sides, there is little theoretical literature which systematically describes the properties of social media. Several articlesstill give a great description of social media characteristics. Mayfield (2008) pointed out five fundamental characteristics shared by almost all media platforms: participation, openness, conversation, community and connectedness. Taprial and Kanwar (2012) identify five properties that are more powerful and distinguish the social media from traditional media. They are accessibility, speed, interactivity, longevity and reach. The research in hand will discuss social media in terms of usability towards health services. Based on the literature on social media usability, five characteristics of social media usability can be summarized as follows:

\section{Connectedness}

Social connectedness focuses on interpersonal, community, and general social ties. From Mayfield's point of view, connectedness is closer to integration in the sense that sites, resources, and people are linked together on different social media platforms.

\section{Openness}

Almost all the social media platforms are free to join and anyone can use social media as a medium to create, edit, communicate and comment on content (Mayfield, 2008). Social media creates an atmosphere that encourages participation and sharing information.

\section{Speed}

One of the advantages of online social networks compared with real life networks is the communication and spread speed. In contrast to traditional WOM, where opinions may disappear immediately, online WOM spreads unfailingly ina viral effect. Contents published on social media platforms are instantaneous and are available to everyone in your network as soon as they are published (Taprial \& Kanwar, 2012).

\section{Accessibility}

Like the traditionalmedia which relies on technology and platforms to function, the same applies to social media, which results from Web 2.0 technologies and user-generated content. With the development of different electronic devices, anyone can access social media anywhere and anytime,solongas it is connected to the internet (Mayfield, 2008).

\section{Participation}

Burgoon et al. (2000) define participation as the extent to which two or more parties are actively engaged in interaction, in contrast to lurking, passive observation or monologues. Social media encourages participation and feedback. One party creates content and shares on the platform to arouse the interest of other parties, encouraging them to actively contribute and engage in feedback. From this point of view, the line between media audiences becomes blurred as everyone can become creators, communicators, readers and buyers of content on the stages, and every individual's personality is moving constantly (Mayfield, 2008).

\subsection{Trust in Social Media}

Trust is an abstract concept and most psychological research looks at interpersonal trust. In marketing, trust is studied from the perspective of relational marketing. In the current research, trust refers to buyer's trust in the usability of social media. As social media relies on the internet for diffusion, it is natural to link previous literature 
about internet trust with the current discussion on trust in social media. Within the context of e-commerce-based internet trust, as the main participants are buyer and e-vendors, trust can be interpreted as the trust in web-based vendors and businesses. The construct of trust is then isolated into two sub-constructs: trusting convictions and trusting goals. Trusting beliefs mean buyers believe that the service provider has at least one characteristic beneficial to them (McKnight \& Chervany, 2002). In terms of characteristics, it includes service providers' willingness and ability to act in the buyer's interest, being honest in transactions and being able and unsurprising at conveying as guaranteed (McKnight \& Chervany, 2002). Trusting intentions refer to the buyerbeing willing to or intending to depend on service providers even though they cannot control them (McKnight \& Chervany, 2002). As part of the e-commerce buyer trust conceptual framework, Mcknight posits suggests cause and effect between trusting beliefs and trustingintentions, following the theory of reasoned action that individuals' beliefs will influence their behavioral intentions. Thus, it can be argued that buyer' trust in social media will influence their apparent value and purchase goals. In addition, the relationship between trust and risk has been explored in many fields, especially in the management literature. Both constructs contain complexities of parallel processing and reverberating feedback, which makes it difficult to establish causal links. The bi-directional causality implies that risk creates an opportunity for trust, while at the same time trust influences risk perception.

Healthcare has always been characterized by trust in the validity andimpartiality of information which the patient can obtain from different sources, primarily from physicians and other healthcare professionals (IMS Institute for Healthcare Informatics, 2014). Thus, information concerning healthcarewhich patients obtain from social media and on the internet varies. The most searched-for terms relate to specific diseases, usually affecting the searcher or one of their relatives (Fox, Duggan, 2013). Additionally, most people who search for healthcare information on the internet are trying to fulfil an unmet need, be it for information or emotional support. Nowadays, healthcare organizations more and moreusesocial media as a tool to build relationships with patients and the general public. Thus, one can observe a change in the online behavior, from a uni-directional telecom of data to a drawing in and relationship-orientated online discussion. Also, due to patients' trust in physicians and the broad reach of social media, healthcare professionals are best placed to launch discussions on healthcare-related topics on the web. Along these lines, social media lets physicians answer questions for many people online.However, it is necessary to differentiate between what is possible for individual physicians, for whom time is a limiting factor, and what can be done by a hospital or network of healthcare professionals (IMS Institute for Healthcare Informatics, 2014). In addition, not all physicians will like the idea of working with new technologies and dealing with patients through social media.Nonetheless, social networks can contribute to a better understanding of day-to-day patient issues and his/her unmet needs, which in turn can contribute to better outcomes for patients. The literature review in this research paper revealed a clear shortage of research on the social media factors influencing the buyer purchasing behavior and buyer trust in health service organisations. The specific references only partially covered the social media factors in health industry. Therefore, the present research attempts to fill a gap in the subject of social media factors in the health industry from the viewpoint of the health services buyers. The research addressed some of the shortcomings in the literature such as the social media factors, to investigate the social media factors impact on buyer trust and buyer purchasing behavior in health services industry.

\subsection{Purchase Intention}

Studies on buyers' buying behavior based on purchase intention have been developed in marketing for more than 20 years. One issue which is not open to debate is whether purchase intention can effectively predict buying behavior. Armstrong, Morwitz and Kumar (2000) applied four intention-based methods to forecast sales of existing buyer goods and services. The results proved that purchase intention is better at forecasting sales than simple extrapolation of past sales trends. Nowadays, in order to better understand buyer behavior, smart companies dig deep into analysis of customers' buying decision process which focuses on their experiences in learning, choosing, using and even disposing of a product (Kotler et al., 2009). Marketers produced a stage model of the buying decision process to simplify the complexity of real-world situations and at the same time capture the key processes and stages of the process. Five key stages, which are problem recognition, information search, evaluation of alternatives, purchase decision and post-purchase behavior, are involved in the model. Marketing researchers generally suggest purchase intention in the purchase decision phase. In this stage, buyers have already formed preferences among various brands and are ready to make their final purchase decisions. However, according to Kotler et al. (2009), preferences and even purchase intentions are not completely reliable predictors of purchase behavior. Two elements may generally intervene between purchase intention and purchase decision. They are attitudes of others and unanticipated situational factors. These two elements are essential in the calculated model proposed in the following part, despite the fact that they are communicated in an unexpected way 


\section{The Research Rationale}

Social media usability plays a crucial role in the healthcare industry as information sources for potential buyers. As a result, this research paper is designed to increase awareness by exploring the factors influencing buyer behavior decision-making concerning the selection of healthcare providers in the healthcare industry in Saudi Arabia. The current research will contribute to the health service marketing discipline in finding out the role of these factors (connectedness, openness, speed, accessibility, and participation) in delivering a better health service. This study will attempt to contribute to the health services marketing by looking at the impact of social medial usability factors and buyer purchasing behavior based on buyer trust. This research will deal with an ignored research area in Saudi Arabia, which is the social medial application in the health services market. Such contributions will be beneficial both academically and professionally.

\section{Objectives of the Research}

The research objectives are:

1. Identifying potential factors that influence buyer-buying behavior beneath social media usability context in the Saudi health market.

2. Investigating the effect of social media usability factors (connectedness, openness, speed, accessibility, and participation) on the buyer buying behavior in the Saudi health market.

\section{Research Hypotheses}

There is a positive significant relationship between social media usability and patient trust.

Five sub-hypotheses were formulated:

1- There is a positive significant relationship between accessibility and patient trust.

2- There is a positive significant relationship between speed and patient trust.

3- There is a positive significant relationship between openness and patient trust.

4- There is a positive significant relationship between connectedness and patient trust.

5- There is a positive significant relationship between participation and patient trust.

6- There is a positive significant relationship between patient trust and patient purchasing behavior.

\section{Research Methodology}

\subsection{Population and Sample}

The research population consisted of all the research population who have visited social media in Jeddah city, in the Kingdom of Saudi Arabia. Hence, all the people were called and invited to participate in the research survey. The number of research questionnaires distributed was 500. The researcher gathered 370 questionnaires which were fully and correctly completed. Respondents typically held purposive samples, yielding a response rate of 74 per cent. Respondents typically held purposive samples. In terms of demographic findings, $(61.4 \%)$ of respondents were males, and the remaining (38.6\%) were females. In terms of the age group of respondents, it is interested to note that $(25.4 \%)$ of them are less than (26) years, whereas (31.1\%) fell into the (26-30) age group, (14.1\%) fell into the (31-35) age group, (13.3\%) fell into the (36-40) age group, (9.4\%) fell into the (41-45) age group, and only (6.8\%) are above this group. As for the educational levels of those target populations, the majority (50.9\%) were university degree holders, and some $(10.1 \%)$ of these have postgraduate degrees. As for the computer literacy of those people, nearly all of them $(96 \%)$ were computer literate, As for the internet accessibility at home/office of these people, the majority (94\%) had internet accessibility at home/office. See Table 1.

Table 1. Characteristics of the sample

\begin{tabular}{lll}
\hline Characteristics & & $\%$ \\
\hline \multirow{2}{*}{ Gender } & Male & 61.4 \\
\cline { 2 - 3 } & Female & 38.6 \\
\hline \multirow{2}{*}{ Age } & 25 and less & 25.4 \\
\cline { 2 - 3 } & $26-30$ & 31.1 \\
\cline { 2 - 3 } & $31-35$ & 14.1 \\
\cline { 2 - 3 } & $36-40$ & 13.3 \\
\hline
\end{tabular}




\begin{tabular}{lll}
\hline & More than 45 & 6.8 \\
\hline Education Level & $\begin{array}{l}\text { High School or } \\
\text { Less }\end{array}$ & 18.9 \\
\cline { 2 - 3 } & & \\
& College Diploma & 20.1 \\
\cline { 2 - 3 } & Bachelor & 50.9 \\
\cline { 2 - 3 } & Postgraduate & 10.1 \\
\hline Computer literacy & Yes & 96 \\
\hline Internet Accessibility & No & 4 \\
\hline & Yes & 94 \\
\cline { 2 - 3 } & No & 6 \\
\hline
\end{tabular}

\subsection{Data Collection}

The research questionnaire was designed based on previous empirical literature. The questionnaire design was pre-tested and redesigned through personal interviews, some of which targeted people by undertaking the pilot study work. The research questionnaire was used as a primary data collection method as shown in Tables 2, 3 and 4 . The components of social media usability, trust, and purchasing behavior items were measured on a five-point Likert-scale ranging from 5 (strongly agree) to 1 (strongly disagree). For the social media usability, trust, and purchasing behavior dimensions, the research respondents were asked to indicate the degree of agreement or disagreement. Multiple items were used to assess their measurement properties. In line with the literature, the scale items selected for the dependent variable were direct measures of trust and also purchasing behavior with influences received from usability of social media as independent variables. This format has been recommended for marketing and social media research. Both the independent and dependent variable(s) deployed in the research are explained in Tables 2, 3 and 4 according to the proposed hypotheses.

Table 2. Independent variables (social media usability)

\section{Connectedness}

Often use the same social media identity to log on different social media platforms. I often share contents from other social media platforms and post it in one social media platform through links. I can edit and communicate information on the social media platform in the form of text, sound, picture, video etc. I often share content from other social media platforms and post it in one social media platform through links.

\section{Openness}

I can use the social media platform free. I can join the social media platform freely. I can get information and publish posts on social media platform freely. I do not need to know special and advanced skills to use social media platforms. I feel easy to join the groups and communities that I am interested in.

\section{Speed}

I can quickly browse the product and information I need on the social media platforms. The contents I publish on social media platforms are available to my friends quickly. I can communicate with my friends on social media platforms instantaneously immediately due to influence of external factors.

\section{Accessibility}

I do not need to know special and advanced skills to use social media platforms. I feel easy to join the groups and communities that I am interested in.

\section{Participation}

I often search product and service information through social media platforms I often make comments or share experiences with my friends about products and services which I have used through social media platforms. I often start a discussion topic about products and services on social media platforms. I often participate in the discussion about products and services proposed by my friends on social media platforms. 
Table 3. Trust

I think information on social media is trustworthy, I think friends on social media are trustworthy; I think the social media I use is trustworthy; I will share my good experience with my friends about buying products or acquiring information on social media platforms.

Table 4. Buyer purchasing behavior

Using social media platforms helps me make decisions better before purchasing health services; using social media platforms increases my interest in buying health services; if I find out that the utility of the products or services is larger than personal devotions in terms of money, time and energy, I will consider buying this health service; I am very likely to buy health services recommended by my friends on social media platforms.

\section{Results Analysis and Discussion}

To test the general hypothesis, a multiple regression was applied. Table 5 shows that:

Table 5. Result of regression for relationship between usability of social media factors and buyer trust

\begin{tabular}{llllll}
\hline Independent variables & $\mathbf{B}$ & Std. Error & Beta & $\mathbf{T}$ & Sig. \\
Accessibility & 0.232 & 0.341 & 0.17 & 2.66 & 0.00 \\
Openness & 0.210 & 0.452 & 0.11 & 2.16 & 0.03 \\
Speed & 0.319 & 0.211 & 0.15 & 2.42 & 0.00 \\
Connectedness & 0.271 & 0.361 & 0.13 & 2.88 & 0.02 \\
Participation & 0.279 & 0.256 & 0.16 & 2.29 & 0.03 \\
$\begin{array}{l}\text { Dependent variable: buyer } \\
\text { trust }\end{array}$ & & $\mathbf{R}^{\mathbf{2}=\mathbf{0 . 8 0 2}}$ & $\begin{array}{l}\text { Adjusted } \\
\mathbf{R}^{2}=\mathbf{0 . 9 0 1}\end{array}$ & $\mathbf{F = 2 6 . 7 1 7}$ & $\mathbf{P}<\mathbf{0 . 0 5}$ \\
\hline
\end{tabular}

$$
Y=B 0+B 1 X 1+B 2 X 2+B 3 X 3+B 4 X 4+B 5 X 5+E
$$

Where:

$\mathrm{Y}=$ The predicted value on the buyer trust;

$\mathrm{B} 0=$ The $\mathrm{Y}$ intercept, the value of $\mathrm{Y}$ when all $\mathrm{Xs}$ are zero;

$\mathrm{X} 1=$ Accessibility;

$\mathrm{X} 2=$ Openness;

$\mathrm{X} 3=$ Speed;

$\mathrm{X} 4=$ Connectedness;

$\mathrm{X} 5=$ Participation;

$\mathrm{B}=$ The various coefficients assigned to the IVs during the regression;

$\mathrm{E}=$ An error term.

Table 6. Result of simple linear regression for relationship between buyer trust and buyer purchasing behavior

\begin{tabular}{|c|c|c|c|c|c|c|}
\hline Independent variables & & B & Std. Error & Beta & $\mathbf{T}$ & Sig. \\
\hline buyer trust & & $\begin{array}{l}0.33 \\
2\end{array}$ & 0.391 & 0.37 & 4.66 & 0.00 \\
\hline $\begin{array}{l}\text { Dependent variable: } \\
\text { purchasing behavior }\end{array}$ & buyer & & $\mathbf{R}^{2}=\mathbf{0 . 7 6 2}$ & $\begin{array}{l}\text { Adjusted } \\
\mathrm{R}^{2}=\mathbf{0 . 8 5 1}\end{array}$ & $F=18.717$ & $\mathbf{P}<0.05$ \\
\hline
\end{tabular}


The fundamental assumption of the current research is that social media usability dimensions, namely accessibility, speed, openness, connectedness, and participation influence buyer trust and outcomes of trust, namely buyer purchasing behavior. A multiple regression modeling approach was proposed as an effective method for studying the relationships. As displayed in Table 5 , the adjusted $\mathrm{R}^{2}$ is 0.901 , suggesting that the five social media usability factors explain close to 90 per cent of the variance for the dimension of buyer trust. Specifically, other tables also show variables have a statistically significant effect on buyer trusts. Of these significant variables, accessibility, speed, openness, connectedness, and participation appear to have the greatest impact on buyer trust. In addition, it predicted that the influence of such factors (accessibility, speed, openness, connectedness, and participation) on buyer trust would differ according to personal variables which are personal characteristics and their experience of social media (as shown in Table 5). The results of the multiple regression analysis signal that there is variation in the effect of social medial usability factors on buyer trusts and empirical evidence in this research suggests that social media usability factors have a significant degree of influence on buyer trust and outcomes of buyer trust. This empirical evidence has provided significant support for the social media, which substantively advocates that social media usability factors have an impact on the outcome of buyer trust. The results empirically substantiate that social media usability factors play a fundamental role in the buyer trust among Saudi buyers.

As shown in Table 6, buyer trust has an effective influence on buyer purchasing behavior. As displayed in Table 6, the adjusted $R^{2}$ is 0.851 , suggesting that the buyer trust factor explains close to 85 per cent of the variance for the dimension of buyer purchasing behavior. In addition, it predicted that the influence of such factors on buyer purchasing behavior would differ according to the personal variables, which are personal characteristics and their experience of social media.

\section{Research Discussion}

In terms of the influence of accessibility on trust, regression coefficient estimates are significant. Also, the influence of accessibility of social media on trust is positive and significant.

The influence of accessibility on buyer's trust in social media is significant, which means there are special skills and efforts spent for the buyer to access and use the platforms, which will significantly influence their trust in social media. Additionally, there is easeinjoining other groups in health cases. This finding is similar to the work of Mayfield (2008), Taprial, and Kanwar (2012).

The speed of using social media has a significant positive influence on buyers' trust. The influence of speed on buyers' trust in social media is significant and positive. The direction of the relation corresponds to the hypothetical direction of relation. Prior research has found positive relations between usability of social media and buyer purchasing behavior (Taprial and Kanwar, 2012).

Regarding the hypothesis of social media openness, the positive influence of openness on buyer trust is supported with statistical significance. However, openness help users to create trust on social media. Other research (Mayfield, 2008) is similarto the current research.

On the subject of participation, this indicates that buyers "participation on social media such as searching for information, chatting, commenting, sharing of information, etc., has a crucial influence on their trust. The direction of the relationship between participation and trust is consistent with the hypothetical direction of relationship. This finding is similar toBurgoon et al. (2000) and Mayfield (2008).

Concerning the hypothesis of social media connectedness, the positive influence of connectedness on buyer trust is supported with statistical significance. Yet, connectedness helps buyer to create trust on social media. Other research (Teixeira, 1992; Mayfield, 2008) is similarto the current research.

The results of the hypothesis regarding trust on buyer purchasing behavior indicates that trust has a positive and significant influence on buyers' purchasing behavior. The direction of the relationship between trust and buyer purchasing behavior is consistent to the hypothetical direction of relationship. This finding is similar to (McKnight \& Chervany, 2002; IMS Institute for Healthcare Informatics, 2014).

\section{Implications}

The theoretical underpinning of this research is based on literature from social media usability and buyer purchasing behavior based on trust. The empirical conclusions drawn from this research are multifaceted and as a result, it is vitally important that health services managers pay attention to the influences of buyer purchasing behavior. Researchers are therefore encouraged to place more focus on the impact of influences stemming from the social media usability and its impact on buyer purchasing behavior within Saudi health market. In addition, adoption of 
social media usability has not been previously identified as crucial inputs for satisfaction by health services providers operating within the health service sector.

\section{Conclusion}

This research intends to contribute original knowledge by investigating the impact of usability of social media on buyer purchasing behavior based on buyer trust in the health service market in Jeddah city, Saudi Arabia. This research contributes to the services marketing discipline in finding out the role of social media usability factors, namely connectedness, openness, speed, accessibility, and participation and buyer purchasing behavior. Contributions found will be helpful for both academics and managers alike. Academically, this work aims to focus academic attention upon a much-neglected domain - the marketing and social media use in health services in Saudi Arabia. There is currently a distinct lack of studies in academia relating to research in the Middle East. This is somewhat surprising when considering that Saudi Arabia has been at the forefront of using social media in the Middle East. In conclusion, with increased informationavailability, changes in how people communicate and a general increase in concerns about one's own health, new technologies are influencing and will continue to influence the healthcare sector. Thus, further investigation is necessary to assess the real impact of social media on the healthcare decisions taken by both healthcare professionals and patients. At present, the fundamental advantages of social media for patients are the possibility of interacting with other patients with the same disease and viewing their symptoms, response to treatments, etc., as well as emotional help and the feeling of companionship, the possibility of better research, which allows them to ask physicians, pharmacistsand insurersmore useful questionsand the possibility of interacting any time, however far you are from other users. On the other hand, the main benefits of social media for healthcare organizations consist of the possibility to provide prompt answers to patients' questions; a better understanding of the patient, the problems he/she faces in his/her everyday activities, his/her fears and unmet needs; the ability to reach a large audience, concerned with medical education and potentially interested in the organization's services.

\section{Refrences}

Armstrong, J, Morwitz, V., \& Kumar, V. (2000). Sales Forecasts for Existing Consumer Products and Services: Do Purchase Intentions Contribute to Accuracy? International Journal of Forecasting, 16(3), 383-397.

Burgoon, J., Bonito, J., Bengssson, B., Ramirez, A., Dunbar, N., \& Miczo, N. (2000). Testing the interactivity model: Processes, partner assessments, and the quality of collaborative work. Journal of Management Information Systems, 16(3), 33-56.

Dykeman, D. (2008). How do you define social media?. Retrieved from http://broadcasting-brain.com/2008/02/09/how-do-you-define-social-media/

Fox, S, Duggan, M. Pew Research Center. (2013). Health online, Jan 15. Retrieved from http://www.pewinternet.org/2013/01/15/health-online-2013/webcite

Jantsch, J. (2008). Duct Tape Marketing. Retrieved from http://www.ducttapemarketing.com/blog/2008/09/25/the-definition-of-social-media/

Kaplan, A. M., \& Haenlein, M. (2010). Uers of the world, unit! The chanllenges and opportunities of social media. Business Horizons, 53, 59-68.

Kotler, P., \& Armstrong, G. (2009). Principles of Marketing. New Jersey: Pearson Prentice Hall.

Mayfield, A. (2008, August 1). What is social media. Icrossing. Retrieved from http://www.icrossing.com/icrossing-what-is-social-media

McKnight, D., \& Chervany, N.L. (2002). What turst means in e-commerce customer relationships: aninterdisciplinary conceptual typology. International Journal of Eletronic Commerce, 6(2), 35-59.

Parr, B. (2008). Ben Parr's Entrepreneurial Musings. Retrieved from http://benparr.com/2008/08/its-time-we-defined-social-media-no-more-arguing-heres-the-definition/

Spallek, H., O’Donnell, J., Clayton, M., Anderson, P., \& A. Krueger. (2010). Paradigm shift or annoying distraction - emerging implications of Web 2.0 for clinical practice. Applied Clinical Informatics, 1, 96-115. http://dx.doi.org/10.4338/ACI-2010-01-CR-0003

Taprial, V., \& Kanwar, P. (2012). Understanding social media. Varinder Taprial \& PriyaKanwar \& Ventus Publishing ApS. 